\title{
Factors Influencing the Implementation of Screening and Brief Interventions for Alcohol Use in Primary Care Practices: A Systematic Review Protocol
}

\author{
Fatores Condicionantes da Implementação da Deteção \\ Precoce e Intervenções Breves no Consumo Excessivo \\ de Álcool nos Cuidados de Saúde Primários: Protocolo de \\ Revisão Sistemática da Literatura
}

Frederico ROSÁRIO $\triangle^{1,2}$, Maria Inês SANTOS ${ }^{3}$, Kathryn ANGUS ${ }^{4}$, Leo PAS ${ }^{5}$, Niamh FITZGERALD 4 Acta Med Port 2018 Jan;31(1):45-50 - https://doi.org/10.20344/amp.9753

\section{ABSTRACT}

Introduction: Alcohol is a leading risk factor contributing to the global burden of disease. National and international agencies recommend evidence-based screening and brief interventions in primary care settings in order to reduce alcohol consumption. However, the majority of primary care professionals do not routinely deliver such interventions.

Objective: To identify factors influencing general practitioners/family physicians' and primary care nurses' routine delivery of alcohol screening and brief intervention in adults.

Material and Methods: A systematic literature search will be carried out in the following electronic databases: Medline, CINAHL, CENTRAL, and PsycINFO. Two authors will independently abstract data and assess study quality using the NIH National Heart, Lung, and Blood Institute quality assessment tools for quantitative studies, and the CASP checklist for qualitative studies. A narrative synthesis of the findings will be provided, structured around the barriers and facilitators identified. Identified barriers and facilitators will be further analysed using the Behavioural Change Wheel/Theoretical Domains Framework.

Discussion: This review will describe the barriers to, and facilitators for, the implementation of alcohol screening and brief interventions by general practitioners/family physicians and nurses at primary care practices. By mapping the barriers and facilitators to the domains of the Behavioural Change Wheel/Theoretical Domains Framework, this review will also provide implementation researchers with a useful tool for selecting promising practitioner-oriented behavioural interventions for improving alcohol screening and brief intervention delivery in primary care.

Conclusion: This review will provide important information for implementing alcohol screening and brief intervention in primary health care.

Systematic Review Registration: PROSPERO CRD42016052681

Keywords: Alcohol Drinking; Alcoholism; Directive Counseling; Health Promotion; Mass Screening; Portugal; Primary Health Care

\section{RESUMO}

Introdução: O consumo de álcool é um importante fator de risco a nível mundial. Apesar de serem recomendadas por muitas instâncias nacionais e internacionais, a deteção e intervenção breve no consumo de álcool ainda não está integrada na prática da maioria dos profissionais de saúde dos Cuidados de Saúde Primários.

Objetivo: Identificar as barreiras e os facilitadores à implementação da deteção e intervenção breve nos consumos de álcool nos Cuidados de Saúde Primários por parte dos Médicos e Enfermeiros de Família.

Material e Métodos: Será realizada uma revisão sistemática da literatura nas seguintes bases de dados: Medline, CINAHL, CENTRAL, e PsycINFO. Dois autores irão, de forma independente, extrair os dados, e avaliar a qualidade dos estudos selecionados. A qualidade dos estudos quantitativos será avaliada através das checklists do NIH National Heart, Lung, and Blood Institute, enquanto a dos estudos qualitativos será avaliada através da checklist CASP. Os resultados serão apresentados numa síntese narrativa, estruturada em torno das barreiras e facilitadores identificados, e analisados à luz dos domínios teóricos da Behavioural Change Wheel/Theoretical Domains Framework.

Discussão: Esta revisão sistemática descreverá as barreiras e os facilitadores à implementação da deteção e intervenção breve nos consumos de álcool nos Cuidados de Saúde Primários. Ao estabelecer a ligação entre estes fatores e os diferentes domínios teóricos da Behavioural Change Wheel/Theoretical Domains Framework, esta revisão sistemática vai facilitar o desenho de programas que visem a implementação destas boas práticas neste nível de cuidados.

Conclusão: Esta revisão contribuirá com informação importante para a implementação da deteção e intervenção breve nos consumos de álcool nos Cuidados de Saúde Primários.

Registo: PROSPERO CRD42016052681

Palavras-chave: Aconselhamento Directivo; Alcoolismo; Consumo de Bebidas Alcoólicas; Cuidados de Saúde Primários; Portugal; Programas de Rastreio; Promoção da Saúde

1. Institute of Preventive Medicine and Public Health. Faculty of Medicine. Lisbon University. Lisbon. Portugal.

2. Tomaz Ribeiro Primary Health Care Center. Dão Lafões Primary Health Care Centers Grouping. Viseu. Portugal.

3. Department of Pediatrics. Tondela-Viseu Hospital Center. Viseu. Portugal.

4. Institute for Social Marketing (ISM). UK Centre for Tobacco \& Alcohol Studies. Faculty of Health Sciences \& Sport. University of Stirling. Stirling. United Kingdom.

5. Academic Centre for General Practice. KU Leuven. Leuven. Belgium.

$\square$ Autor correspondente: Frederico Rosário. fredmbr@gmail.com

Recebido: 02 de outubro de 2017 - Aceite: 19 de dezembro de 2017 | Copyright @ Ordem dos Médicos 2018 


\section{INTRODUCTION}

Alcohol is a leading risk factor contributing to the global burden of disease. ${ }^{1}$ The World Health Organization estimates that 3.3 million people die each year because of alcohol consumption. ${ }^{2}$ This represents $5.9 \%$ of all deaths worldwide. Alcohol also contributes to more than 200 disease and injury conditions, accounting for $5.1 \%$ of the global burden of disease and injury. Alcohol-related harm increases exponentially with the average daily consumption, ${ }^{3}$ therefore even small reductions can substantially decrease the risk of dying due to alcohol.

Screening and brief interventions $(\mathrm{SBI})$ in primary care settings has long been advocated for preventing harm from excessive alcohol use. Several randomized controlled trials and meta-analysis have found alcohol SBI to be highly effective, cost-effective, and even cost-saving. ${ }^{4-11}$ However, there has been recent debate concerning the validity of this effectiveness evidence. ${ }^{12,13}$ Most trials use self-reported alcohol consumption as their primary outcome measure rather than alcohol-related morbidity or mortality problems, and such self-reported outcomes may be subject to social desirability bias or other research participation effects. ${ }^{14,15}$ Furthermore, the active ingredients of SBI have yet to be determined. ${ }^{16,17}$ Notwithstanding these discussions, it is clear that alcohol increases the risk of and/ or exacerbates many conditions that present in primary care.$^{3,18}$ Furthermore, of the many patients visiting primary care who are at-risk drinkers, ${ }^{19-21}$ few currently receive any alcohol-related advice or intervention from their doctor. ${ }^{22-28}$ They are therefore denied the opportunity to understand the risks and make an informed decision about whether or not to cut down.

Several studies have examined barriers and facilitators affecting whether or not primary care professionals address alcohol use with patients. Lack of training, lack of time, lack of motivation, and lack of suitable counselling materials are among the most commonly cited barriers ${ }^{23,29-37}$; whereas having patients who seek advice for alcohol issues, more training, and ready availability of support services, screening and counselling materials are commonly reported facilitators. ${ }^{23,30,31,38}$ Whilst several studies have documented or tested training, financial or other interventions designed to increase the implementation of alcohol SBI in primary care, ${ }^{26,39}$ few are theoretically informed ${ }^{40}$ and reporting of the content of training and follow up support is often poor. ${ }^{41}$ Johnson et al reviewed the barriers and facilitators for implementing alcohol screening and brief intervention in $2009,{ }^{42}$ giving priority to studies judged to best inform the UK practice. The review reported on 47 articles focusing on different healthcare settings. Lack of resources, absence of training and support from management, and workload were the main barriers to implementation. Adequate resources, training and the identification of those at risk without stereotyping were pointed as the main facilitators. This review will update the Johnson et al review, employ a more comprehensive search strategy, and have an international focus.
Our review will also be theoretically informed as it is important to understand how identified barriers and facilitators fit with theoretical understandings of behaviour change in order to inform the design of implementation interventions that may have a higher chance of successfully changing practitioner behaviour. There are many theories of behaviour change, though with considerable overlap between them, and striking differences in terminology, definitions and key constructs. ${ }^{43}$ Several frameworks have been proposed to overcome these limitations including ${ }^{43-46}$ the Behaviour Change Wheel (BCW), which is comprehensive, coherent and widely used. The BCW is linked to an overarching model of behaviour and can be further expanded by the Theoretical Domains Framework (TDF), which was derived from an analysis of 33 theories of behaviour change, and comprises fourteen domains consisting of 84 component constructs of behaviour change. ${ }^{47}$ This review will therefore analyse the identified barriers and facilitators using the BCW/TDF system as outlined further in the methods section below.

\section{OBJECTIVE}

This review aims to identify factors influencing general practitioners/family physicians' and primary care nurses' routine delivery of alcohol screening and brief interventions in adults. The specific research questions we will address are:

1. What are the barriers to routine delivery of alcohol screening and brief interventions by general practitioners/ family physicians and nurses in primary care settings?

2. What factors help to facilitate routine delivery of alcohol screening and brief interventions by general practitioners/family physicians and nurses in primary care settings?

3. How do the identified barriers and facilitators map to the BCW/TDF frameworks?

\section{MATERIAL AND METHODS}

The review methods are outlined here in accordance with the Preferred Reporting Items for Systematic Review and Meta-Analysis Protocols (PRISMA-P) statement ${ }^{48,49}$ [see Appendix 1 (PRISMA-P Checklist): https://www. actamedicaportuguesa.com/revista/index.php/amp/article/ view/9753/5312].

\section{Inclusion and exclusion criteria}

Study designs. Studies with abstracts published in a peer-reviewed scientific journal which report primary data will be included; studies without abstracts and studies published as conference abstracts will be excluded. If more than one publication describing a single study and presenting the same data is found, then only the most recent publication will be included. The review will consider quantitative and qualitative studies. Quantitative studies will be included if they are randomized controlled trials, beforeafter studies with no control group, cohort, case-control, or 
cross-sectional studies. Qualitative studies will be included if they use Delphi methodology, focus groups, in-depth interviews, or semi-structured interviews.

Participants. Studies will be included if the participants include general practitioners/family physicians or nurses working in primary care practices. 'Primary care practices' will be defined as follows, adapted from the definition of the American Academy of Family Physicians. ${ }^{50}$ Primary care practices typically serve as the patient's first point of entry into the health care system and provide services such as health promotion, disease prevention, health maintenance, counselling, patient education, diagnosis and treatment of acute and chronic illnesses. Primary care practices are generally located in the community of the patients, thereby facilitating access to healthcare. The structure of the primary care practice may include a team of physicians and other health professionals.

Studies relating only to medical practitioners other than general practitioners/family physicians will be excluded. Studies relating only to medical practitioners or nurses not working in primary care practices, or only to other professionals working in primary care will also be excluded.

Interventions. The targeted intervention will be the implementation of activities aiming to reduce alcohol consumption, conducted in primary care practices, and defined as follows:

a) early identification of patients who drink at a level deemed to merit intervention as defined by the authors;

b) brief interventions, defined as one to four sessions of a structured conversation (e.g. 5 - 30 minutes each) about alcohol with patients from a).

Outcomes. The outcomes of interest in this review are barriers and facilitators potentially influencing the implementation of screening and brief interventions for alcohol use. Studies will be included if they report from primary data at least one clearly defined barrier or facilitator potentially influencing the implementation of the interventions as defined above. In this review, barriers are clearly defined factors that decrease the probability of the implementation of the intervention by general practitioners/family physicians or nurses working in primary care practices. Facilitators are clearly defined factors that increase the probability of the implementation of the intervention by general practitioners/family physicians or nurses working in primary care practices.

Studies will be excluded if they report on: implementation barriers and/or facilitators for patients with conditions that present rarely to primary care providers; factors influencing implementation on populations with specific co-morbidities such as HIV, autoimmune diseases, psychosis, personality disorders, post-traumatic stress or major anxiety disorders, dementia (list not exhaustive) and; factors influencing the implementation of the intervention on people who are less than 18 years of age, or in which this age group is included and no clear distinction can be made between the barriers to implementation in this age group and those aged 18 or above.
Setting. The intervention must be offered in a primary care practice (as defined above). All other settings will be excluded.

Language. Studies will be included if they are reported in any of the following languages: English, French, Spanish, and Portuguese. Studies in other languages will be excluded.

\section{Information sources and search strategy}

The following electronic databases will be searched, from onset of literature database until May 2016, for studies meeting the inclusion criteria stated above: MEDLINE, CINAHL, Cochrane Central Register of Controlled Trials (CENTRAL), and PsycINFO. The search strategy will be developed with a health information specialist (KA), based on a list of relevant keywords identified from an exploratory search of the literature and by exploring the Medical Subject Headings (MeSH terms) of the US National Library of Medicine. The final search will be performed by KA, after adapting the MEDLINE strategy to the syntax of the other databases [see Appendix 2 (Search strategy): https://www. actamedicaportuguesa.com/revista/index.php/amp/article/ view/9753/5313]. To ensure literature saturation, we will scan the reference lists of relevant systematic reviews and meta-analysis identified through the search for potentially eligible papers.

\section{Data management and study selection}

The results of the literature search will be uploaded to Reference Manager Version 10 software. One reviewer will scan the titles and/or abstracts to eliminate duplicate results. Next, two reviewers will independently screen titles and abstracts of identified references. Studies will be excluded if they: 1) do not have a title and an abstract; 2) are not peer-reviewed and published in an academic journal in the public domain; 3) are not published in one of the following languages: English, French, Spanish, or Portuguese; 4) do not focus on alcohol; 5) do not have a qualitative or quantitative methodology as defined above; 6) do not focus on the implementation of the intervention as defined above in the general primary care adult population or; 7) do not focus on barriers and/or facilitators reported by general practitioners/family physicians or nurses working in primary care practice. Disagreements will be resolved through consensus. If consensus cannot be reached, a third reviewer will be contacted. Full text copies of all studies meeting inclusion criteria and of those with unclear eligibility based on title and abstract will be sought and the selection process repeated. Reasons for excluding papers from the analysis will be recorded in a table describing the characteristics of the studies excluded. Reviewers will not be blinded for any aspect of the studies identified and selected. This review will be reported in accordance with the PRISMA guidelines which will include a flow diagram (Fig. 1) and a table detailing the studies selected. ${ }^{51-52}$ 


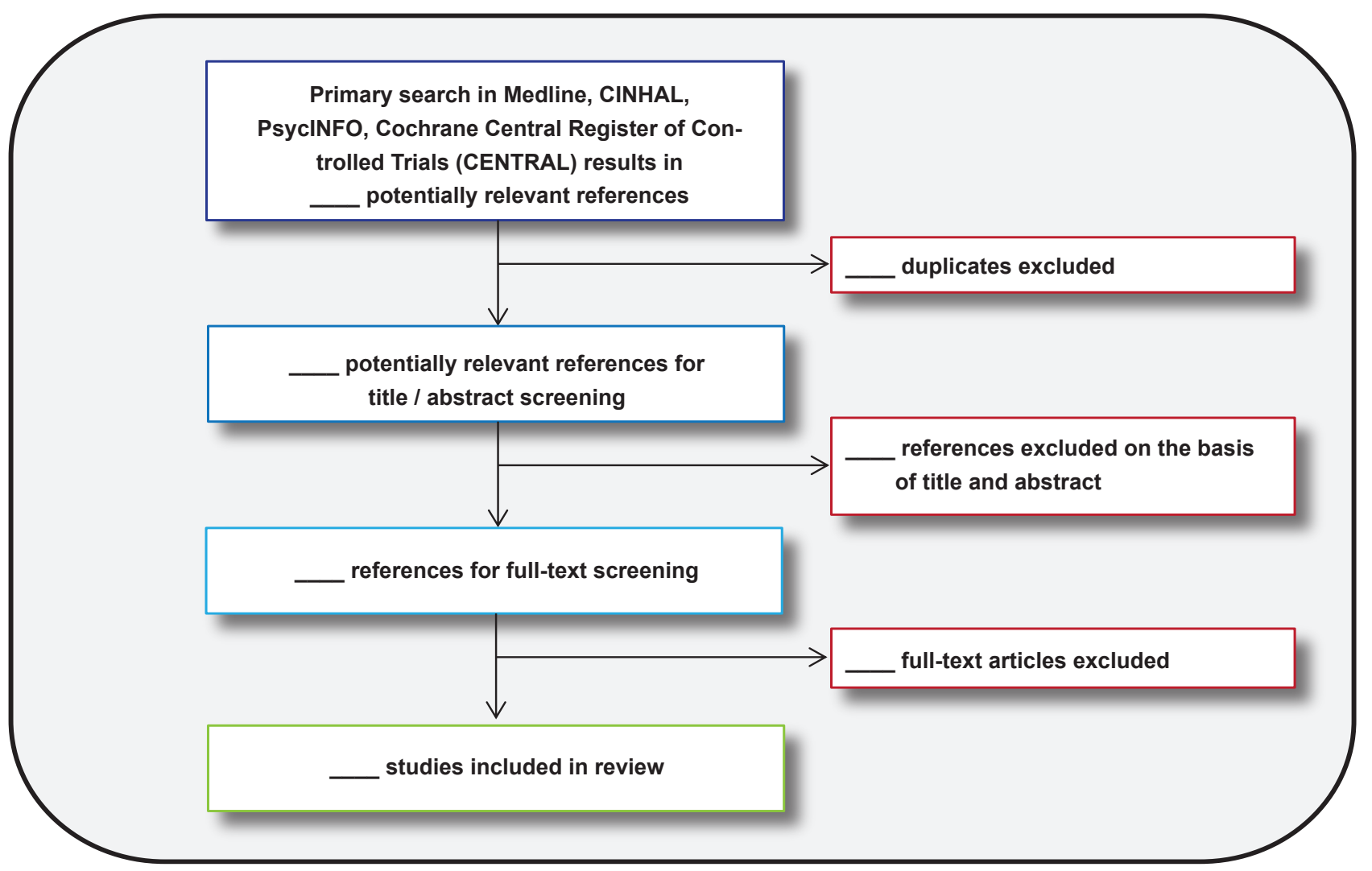

Figure 1 - Flow diagram of screening process

\section{Data extraction}

Two authors will independently extract data to a data extraction form specifically designed for this review and later entered into a Microsoft Excel sheet. Disagreements will be resolved as described above.

Studies will be grouped according to whether they are quantitative or qualitative. Data to be extracted will include: first author; year of publication; title; country of origin; language of publication; main objective of the study; study design; study sample (sampling strategy, type and number of care providers, response/attrition rate); operational definition of identified barriers and facilitators studied; main results; relation with outcomes or process variables in intervention studies.

\section{Assessment of methodological quality}

To inform our synthesis of the evidence a critical appraisal of the validity of the included qualitative and quantitative studies will be conducted. Two reviewers will independently assess the methodological quality of the studies selected for the systematic review. Disagreements will be resolved through consensus. If consensus cannot be reached, a third reviewer will be contacted.

Quantitative studies will be appraised with the $\mathrm{NIH}$ National Heart, Lung, and Blood Institute quality assessment tools for controlled intervention studies, beforeafter (pre-post) studies with no control group, observational cohort and cross-sectional studies and case-controlled studies.$^{53}$ The quality of qualitative studies will be assessed with the critical appraisal skills program (CASP) qualitative research checklist. ${ }^{54}$ As this review will consider quantitative and qualitative studies, we will additionally appraise all selected studies as recommended by the Supplementary Guidance for Inclusion of Qualitative Research in Cochrane Systematic Reviews of Interventions. ${ }^{55}$

\section{Data synthesis}

The review will start by reporting the results of the literature searched. PRISMA flowcharts and tables will be used to present reasons for inclusion and exclusion, as well as to describe the methodology of studies included. Next, a descriptive analysis of the barriers and facilitators extracted from the studies selected will be conducted. The classification of the retained factors will be achieved through consensus between two independent research team members. If any disagreement persists a third member of the research team will be contacted. The results of the review will be reported in a table and a narrative synthesis of the findings will be provided, structured around the barriers and facilitators identified, the professional group, the population target group, and the alcohol related intervention (detection/advice/follow up). The barriers and facilitators will be further analysed using the BCW/TDF framework. Due to the nature of the review, we do not anticipate conducting a meta-analysis.

\section{DISCUSSION}

This systematic review will describe the barriers and facilitators for implementing alcohol screening and brief interventions by general practitioners/family physicians 
and nurses in primary care practices. Knowing the factors influencing the implementation of alcohol screening and brief advice in primary care is important for designing effective implementation programs. By mapping the barriers and facilitators to the domains of the BCW/TDF framework, this review will also provide implementation researchers with a useful tool for selecting promising practitioneroriented behavioural interventions for improving alcohol screening and brief intervention. If possible, we will use this approach to analyse if the barriers and facilitators suggest gaps in current theory and/or if there are current theoretical concepts not reflected in the literature.

Due to the mixed methods in the studies under review, and our emphasis on identifying, rather than quantifying, the impact of specific barriers and facilitators, data will not be pooled quantitatively or meta-analysed. For the same reason, studies will not be excluded based on their quality, but the quality of the included studies will be assessed to enable those using the findings to better understand and assess the value of the findings from each study and overall.

\section{CONCLUSION}

This review will identify gaps in empirical and theoretical understanding about the barriers and facilitators of the delivery of alcohol SBI in primary care practices. The findings will be of interest to those designing, commissioning or implementing interventions to promote such interventions in primary care, including training. It will also help to open one of the 'black boxes' that has been identified as meriting further investigation in relation to alcohol SBI: "what should primary care clinicians say and how should they say it when addressing alcohol consumption with patients; and secondly, what training do they need to enable them to do so effectively?". 56 Randomized controlled trials investigating the effectiveness

\section{REFERENCES}

1. Lim SS, Vos T, Flaxman AD, Danaei G, Shibuya K, Adair-Rohani H, et al. A comparative risk assessment of burden of disease and injury attributable to 67 risk factors and risk factor clusters in 21 regions, 19902010: a systematic analysis for the Global Burden of Disease Study 2010. Lancet. 2012;380:2224-60.

2. World Health Organization. Global status report on alcohol and health. 2014. [2017 Mar 22]. Available from: http://apps.who.int/iris/ bitstream/10665/112736/1/9789240692763_eng.pdf.

3. Rehm J, Gmel G, Probst C, Shield KD. Lifetime-risk of alcoholattributable mortality based on different levels of alcohol consumption in seven European countries. Implications for low-risk drinking guidelines. Toronto, On, Canada: Centre for Addiction and Mental Health. 2015. [Accessed 2017 Mar 22.] Available from: https://www.camh.ca/en/ research/news_and_publications/reports_and_books/Documents/ Lifetime\%20Risk\%20of\%20Alcohol-Attributable\%20Mortality.pdf.

4. Ballesteros J, Duffy JC, Querejeta I, Arino J, Gonzalez-Pinto A. Efficacy of brief interventions for hazardous drinkers in primary care: systematic review and meta-analyses. Alcohol Clin Exp Res. 2004;28:608-18.

5. Bertholet N, Daeppen JB, Wietlisbach V, Fleming M, Burnand B. Reduction of alcohol consumption by brief alcohol intervention in primary care: systematic review and meta-analysis. Arch Intern Med. 2005;165:986-95.

6. Cuijpers P, Riper H, Lemmers L. The effects on mortality of brief interventions for problem drinking: a meta-analysis. Addiction. 2004;99:839-45.

7. Gordon L, Graves N, Hawkes A, Eakin E. A review of the cost- of interventions need to address barriers and facilitators to recruit primary care practitioners and ensure they deliver the interventions under study; those investigating training should be designing the training based on the best available evidence. A comprehensive and up to date understanding of the barriers and facilitators relating to alcohol SBI delivery is therefore important for both research and practice in this field.

\section{ACKNOWLEDGEMENTS}

Niamh Fitzgerald and Kathryn Angus are employed by the Institute for Social Marketing, which is part of the UK Centre for Tobacco and Alcohol Studies (http://www.ukctas. net).

Funding for UKCTAS from the British Heart Foundation, Cancer Research UK, the Economic and Social Research Council, the Medical Research Council and the National Institute of Health Research, under the auspices of the UK Clinical Research Collaboration, is gratefully acknowledged.

\section{PROTECTION OF HUMANS AND ANIMALS}

The authors declare that the procedures were followed according to the regulations established by the Clinical Research and Ethics Committee and to the Helsinki Declaration of the World Medical Association.

\section{DATA CONFIDENTIALITY}

The authors declare having followed the protocols in use at their working center regarding patients' data publication.

\section{CONFLICTS OF INTEREST}

None.

\section{FUNDING SOURCES}

This study has no funding.

effectiveness of face-to-face behavioural interventions for smoking, physical activity, diet and alcohol. Chronic IIIn. 2007;3:101-29.

8. Kaner EF, Beyer F, Dickinson HO, Piennar E, Campbell F, Schlesinger $C$, et al. Effectiveness of brief alcohol interventions in primary care populations. Cochrane Database Syst Rev. 2007;18:CD004148.

9. Purshouse RC, Brennan A, Rafia R, Latimer NR, Archer RJ, Angus CR, et al. Modelling the cost-effectiveness of alcohol screening and brief interventions in primary care in England. Alcohol Alcohol. 2013;48:1808.

10. Solberg LI, Maciosek MV, Edwards NM. Primary care intervention to reduce alcohol misuse ranking its health impact and cost effectiveness. Am J Prev Med. 2008;34:143-52.

11. Angus $C$, Thomas $C$, Anderson P, Meier PS, Brennan A. Estimating the cost-effectiveness of brief interventions for heavy drinking in primary health care across Europe. Eur J Public Health. 2017;27:345-51.

12. McCambridge J, Saitz R. Rethinking brief interventions for alcohol in general practice. BMJ. 2017;356:j116.

13. Glass JE, Andreasson S, Bradley KA, Finn SW, Williams EC, Bakshi AS, et al. Rethinking alcohol interventions in health care: a thematic meeting of the International Network on Brief Interventions for Alcohol \& Other Drugs (INEBRIA). Addict Sci Clin Pract. 2017;12:14.

14. McCambridge J, Kypri K. Can simply answering research questions change behaviour? Systematic review and meta analyses of brief alcohol intervention trials. PloS one. 2011;6:e23748.

15. McCambridge J, Kypri K, Elbourne D. Research participation effects: a skeleton in the methodological cupboard. J Clin Epidemiol. 2014;67:845- 
16. Gaume J, McCambridge J, Bertholet N, Daeppen JB. Mechanisms of action of brief alcohol interventions remain largely unknown - a narrative review. Front Psychiatry. 2014;5:108.

17. McCambridge J, Rollnick S. Should brief interventions in primary care address alcohol problems more strongly? Addiction. 2014;109:1054-8.

18. Patel V, Chisholm D, Parikh R, Charlson FJ, Degenhardt L, Dua T, et al. Addressing the burden of mental, neurological, and substance use disorders: key messages from Disease Control Priorities, $3^{\text {rd }}$ edition. Lancet. 2016;387:1672-85.

19. Hoertel N, Crochard A, Rouillon F, Limosin F. L'alcool en France et ses conséquences médicales et sociales: regard de l'entourage et des médecins généralistes. L'Encephale. 2014;40:S11-31.

20. Ribeiro C. A medicina geral e familiar e a abordagem do consumo de álcool detecção e intervenções breves no âmbito dos cuidados de saúde primários. Acta Med Port. 2011;24:355-68.

21. Bulc M, Svab I, Godycki-Cwirko M. Factors that affect readiness to change lifestyle: a 22-country survey from primary care. Eur J Gen Pract.. 2015;21:33-8.

22. Brown J, West R, Angus C, Beard E, Brennan A, Drummond C, et al. Comparison of brief interventions in primary care on smoking and excessive alcohol consumption: a population survey in England. $\mathrm{Br} \mathrm{J}$ Gen Pract. 2016;66:e1-9.

23. Wilson GB, Lock CA, Heather N, Cassidy P, Christie MM, Kaner EF. Intervention against excessive alcohol consumption in primary health care: a survey of GPs' attitudes and practices in England 10 years on. Alcohol Alcohol. 2011;46:570-7.

24. Cheeta S, Drummond C, Oyefeso A, Phillips T, Deluca P, Perryman K, et al. Low identification of alcohol use disorders in general practice in England. Addiction. 2008;103:766-73.

25. Geirsson M, Bendtsen P, Spak F. Attitudes of Swedish general practitioners and nurses to working with lifestyle change, with special reference to alcohol consumption. Alcohol Alcohol. 2005;40:388-93.

26. Hilbink M, Voerman G, van Beurden I, Penninx B, Laurant M. A randomized controlled trial of a tailored primary care program to reverse excessive alcohol consumption. J Am Board Fam Med. 2012;25:712-22.

27. Roche AM, Richard GP. Doctors' willingness to intervene in patients' drug and alcohol problems. Soc Sci Med. 1991;33:1053-61.

28. Drummond C, Wolstenholme A, Deluca P, Davey Z, Donoghue K, Elzerbi $C$, et al. Alcohol interventions and treatment in Europe. In Anderson P, Braddick F, Reynolds J, Gual A, editors. Alcohol Policy in Europe: Evidence from AMPHORA. 2013. $2^{\text {nd }}$ ed. The AMPHORA Project. [Accessed 2017 Mar 22]. Available from: http://amphoraproject. net/w2box/data/e-book/Chapter\%209\%20-\%20AM_E-BOOK_2nd\%20 edition\%20-\%20July\%202013.pdf.

29. Rosario F, Wojnar M, Ribeiro C. Can doctors be divided into groups based on their attitudes to addressing alcohol issues in their patients? Analyses from a aurvey of Portuguese general practitioners. Subst Use Misuse. 2017;52:233-9

30. Rosario F, Wojnar M, Ribeiro C. Differences between groups of family physicians with different attitudes towards at-risk drinkers: a post hoc study of the ODHIN survey in Portugal. Int J Family Med. 2016;2016:3635907.

31. Anderson P, Wojnar M, Jakubczyk A, Gual A, Reynolds J, Segura L, et al. Managing alcohol problems in general practice in Europe: results from the European ODHIN survey of general practitioners. Alcohol Alcohol. 2014;49:531-9

32. Aalto M, Pekuri P, Seppa K. Obstacles to carrying out brief intervention for heavy drinkers in primary health care: a focus group study. Drug Alcohol Rev. 2003;22:169-73

33. Aira M, Kauhanen J, Larivaara P, Rautio P. Factors influencing inquiry about patients' alcohol consumption by primary health care physicians: qualitative semi-structured interview study. Fam Pract. 2003;20:270-5.

34. Anderson P, Kaner E, Wutzke S, Funk M, Heather N, Wensing M, et al. Attitudes and managing alcohol problems in general practice: an interaction analysis based on findings from a WHO collaborative study. Alcohol Alcohol. 2004;39:351-6.

35. Babor TF, Higgins-Biddle JC. Alcohol screening and brief intervention: dissemination strategies for medical practice and public health. Addiction. 2000;95:677-86.

36. Kaner EF, Heather N, McAvoy BR, Lock CA, Gilvarry E. Intervention for excessive alcohol consumption in primary health care: attitudes and practices of English general practitioners. Alcohol Alcohol. 1999;34:55966.

37. Nilsen P, Aalto M, Bendtsen P, Seppa K. Effectiveness of strategies to implement brief alcohol intervention in primary healthcare. A systematic review. Scand J Prim Health Care. 2006;24:5-15.

38. McAvoy B, Donovan R, Jalleh G, Sauders J, Wutzke S, Lee N, et al General Practitioners, Prevention and Alcohol - a powerful cocktail? Facilitators and inhibitors of practising preventive medicine in general and early intervention for alcohol in particular: a 12-nation key informant and general practitioner study. Drugs: education, prevention and policy. 2001;8:103-17.

39. Keurhorst MN, Anderson P, Spak F, Bendtsen P, Segura L, Colom J, et al. Implementing training and support, financial reimbursement, and referral to an internet-based brief advice program to improve the early identification of hazardous and harmful alcohol consumption in primary care (ODHIN): study protocol for a cluster randomized factorial trial. Implement Sci. 2013;8:11.

40. Michie S, Prestwich A. Are interventions theory-based? Development of a theory coding scheme. Health Psychol. 2010 Jan;29:1-8.

41. Fitzgerald N, Angus K, Bauld L. Reported training in alcohol brief intervention trials: a systematic narrative synthesis. Addiction science \& clinical practice. 2016;11:A28.

42. Johnson M, Jackson R, Guillaume L, Meier P, Goyder E. Barriers and facilitators to implementing screening and brief intervention for alcohol misuse: a systematic review of qualitative evidence. J Public Health. 2010;33:412-21.

43. Damschroder LJ, Aron DC, Keith RE, Kirsh SR, Alexander JA, Lowery JC. Fostering implementation of health services research findings into practice: a consolidated framework for advancing implementation science. Implement Sci. 2009;4:50.

44. Department for Environment, Food and Rural Affairs. A framework for pro-environmental behaviours. 2008. [Accessed 2017 May 07.] Available from: https://www.gov.uk/government/uploads/system/uploads/ attachment_data/file/69277/pb13574-behaviours-report-080110.pdf.

45. Institute for Government: MINDSPACE; Influencing behaviour through public policy. Institute for Government, the Cabinet Office. 2010. [Accessed 2017 Apr 04] Available from https://www.instituteforgovernment.org.uk/ sites/default/files/publications/MINDSPACE.pdf.

46. Michie S, van Stralen MM, West R. The behaviour change wheel: a new method for characterising and designing behaviour change interventions. Implement Sci. 2011;6:42.

47. Cane J, O'Connor D, Michie S. Validation of the theoretical domains framework for use in behaviour change and implementation research. Implement Sci. 2012;7:37

48. Moher D, Shamseer L, Clarke M, Ghersi D, Liberati A, Petticrew M, et al. Preferred reporting items for systematic review and meta-analysis protocols (PRISMA-P) 2015 statement. Systematic reviews. 2015;4:1.

49. Shamseer L, Moher D, Clarke M, Ghersi D, Liberati A, Petticrew M, et al. Preferred reporting items for systematic review and meta-analysis protocols (PRISMA-P) 2015: elaboration and explanation. BMJ. 2015;349:g7647.

50. Primary Care Definition. AAFP. [Accessed 2017 May 31]. Available from: http://www.aafp.org/about/policies/all/primary-care.html\#2.

51. Liberati A, Altman DG, Tetzlaff J, Mulrow C, Gøtzsche PC, loannidis JP, et al. The PRISMA statement for reporting systematic reviews and metaanalyses of studies that evaluate healthcare interventions: explanation and elaboration. BMJ. 2009;339:b2700.

52. Moher D, Liberati A, Tetzlaff J, Altman DG, Group P. Preferred reporting items for systematic reviews and meta-analyses: the PRISMA statement. BMJ. 2009;339:b2535.

53. Study Quality Assessment Tools. National Heart, Lung and Blood Institute. 2014. [Accessed 2017 May 31]. Available from: https://www. nhlbi.nih.gov/health-pro/guidelines/in-develop/cardiovascular-riskreduction/tools.

54. CASP Checklists. Critical Appraisal Skills Programme (CASP). 2017. [Accessed 2017 May 31]. Available from: http://www.casp-uk.net/casptools-checklists.

55. Hannes K. Chapter 4: Critical appraisal of qualitative research. In Noyes J, Booth A, Hannes K, Harden A, Harris J, Lewin S, Lockwood $C$, editors. Supplementary guidance for inclusion of qualitative research in Cochrane systematic reviews of interventions. version 1 (updated August 2011). Cochrane Collaboration Qualitative Methods Group. 2011. [Accessed 2017 Aug 02]. Available from: http://cqrmg.cochrane. org/supplemental-handbook-guidance.

56. Fitzgerald N. Commentary on Anderson et al. (2016): The question is not just whether to incentivize and train practitioners on alcohol screening and brief advice, but how? Addiction. 2016:111:1946-7. 